\title{
BMJ Open Assessing knowledge, attitude, practice and training related to COVID-19: a cross-sectional survey of frontline healthcare workers in Nigeria
}

\author{
Theddeus Iheanacho, ${ }^{1}$ Elina Stefanovics (D) , ${ }^{1}$ Ugochi Genevieve Okoro, ${ }^{2}$ \\ Udo Ego Anyaehie, ${ }^{3}$ Paschal Okuchi Njoku, ${ }^{4}$ Anthony lkenna Adimekwe (D) , \\ Kingsley Ibediro, ${ }^{6}$ Glenn A Stefanovics, ${ }^{7}$ Angela Haeny (1) , ${ }^{1}$ Asti Jackson, ${ }^{1}$ \\ Norbert Ndubuisi Unamba, ${ }^{8}$ Godsent Isiguzo, ${ }^{9}$ Chinedu Chukwukiro Chukwu, ${ }^{10}$ \\ Ugochukwu Bond Anyaehie, ${ }^{11}$ Thomas Terence Mbam, ${ }^{12}$ Chinyere Osy-Eneze, ${ }^{13}$ \\ Ebere Otuomasirichi Ibezim ${ }^{14}$
}

To cite: Iheanacho T, Stefanovics E, Okoro UG, et al. Assessing knowledge, attitude, practice and training related to COVID-19: a cross-sectional survey of frontline healthcare workers in Nigeria. BMJ Open 2021;11:e050138. doi:10.1136/ bmjopen-2021-050138

- Prepublication history and additional supplemental material for this paper are available online. To view these files, please visit the journal online (http://dx.doi.org/10.1136/ bmjopen-2021-050138)

Received 08 March 2021 Accepted 10 September 2021

Check for updates

(c) Author(s) (or their employer(s)) 2021. Re-use permitted under CC BY-NC. No commercial re-use. See rights and permissions. Published by BMJ.

For numbered affiliations see end of article.

Correspondence to Dr Theddeus Iheanacho; theddeus.iheanacho@yale.edu

\section{ABSTRACT}

Objectives Healthcare workers (HCWs) are at the frontline of efforts to treat those affected by COVID-19 and prevent its continued spread. This study seeks to assess knowledge, attitude and practice (KAP) as well as training needs and preferences related to COVID-19 among frontline HCWs in Nigeria.

Setting A cross-sectional survey was carried out among 1852 HCWs in primary, secondary and tertiary care settings across Nigeria using a 33-item questionnaire.

Participants Respondents included doctors, nurses, pharmacy and clinical laboratory professionals who have direct clinical contact with patients at the various healthcare settings.

Analysis Exploratory factor analysis (EFA) was used to establish independent factors related to COVID-19 KAP. Analysis of variance was used to identify any differences in the factors among different categories of HCWs.

Results EFA identified four factors: safety and prevention (factor 1), practice and knowledge (factor 2), control and mitigation (factor 3 ) and national perceptions (factor 4). Significant group differences were found on three factors: Factor $1(F(1,1655)=5.79, p=0.0006)$, factor $3(F(1,1633)=12.9, p<0.0 .0001)$ and factor 4 $(F(1,1655)=7.31, p<0.0001)$ with doctors scoring higher on these three factors when compared with nurses, pharmaceutical workers and medical laboratory scientist. The most endorsed training need was how to reorganise the workplace to prevent spread of COVID-19. This was chosen by $61.8 \%$ of medical laboratory professionals, $55.6 \%$ of doctors, $51.7 \%$ of nurses and $51.6 \%$ of pharmaceutical health workers. The most preferred modes of training were webinars and conferences.

Conclusion There were substantial differences in KAP regarding the COVID-19 pandemic among various categories of frontline HCWs surveyed. There were also group differences on COVID-19 training needs and preferences. Tailored health education and training aimed at enhancing and updating COVID-19 KAP are needed, particularly among non-physician HCWs.

\section{STRENGTHS AND LIMITATIONS OF THIS STUDY}

$\Rightarrow$ This is a nationwide study with representation of healthcare workers (HCWs) across various regions of the country.

$\Rightarrow$ We completed exploratory factor analysis to identify key domains related to COVID-19 knowledge, attitude, practice and prevention strategies among HCWs in Nigeria.

$\Rightarrow$ Analysis of covariance was conducted using the four key factors (safety and prevention, practice and knowledge, control and mitigation, national perceptions) and not individual survey items.

$\Rightarrow$ Distribution of the survey electronically through the health professional associations' WhatsApp groups, Facebook pages and Twitter accounts enabled wider reach.

$\Rightarrow$ The study used voluntary, non-random, convenience sample of respondents with varying educational backgrounds working in different healthcare settings and locations across Nigeria.

\section{INTRODUCTION}

COVID-19 is caused by a novel human coronavirus (SARS-COV-2). ${ }^{1}$ COVID-19 was declared a pandemic by the WHO on 11 March 2020 and since then it has continued to have disruptive impact worldwide on healthcare delivery, public health and economic activities. $^{2}$ As of 23 November 2020, according to the Johns Hopkins University Coronavirus Resource Center, WHO and Nigeria Center for Disease Control (NCDC), the disease had affected 58751191 individuals globally with 1389770 deaths recorded. Out of 191 countries, regions and sovereignty being tracked, Nigeria ranked 81 st with the number of confirmed cases at 85560 and death rate of $1.5 \%$ with 1267 deaths as of 30 December 
$2020 .^{3-5}$ Additionally, the number of confirmed cases in Nigeria continued to rise daily. ${ }^{5}$ Among healthcare workers (HCWs) in Nigeria, data for COVID-19 infections and deaths are sparse. On 30 December 2020, media reports showed that at least $2175 \mathrm{HCWs}$ contracted the disease and 22 doctors died from it though overall fatality among HCWs remain unknown. ${ }^{6-8}$

Various teams of HCWs (namely, nurses, doctors, laboratory staff and pharmacists) who have direct, face-to-face contact with patients are at the frontline of the medical response to the COVID-19 pandemic. ${ }^{9}$ These HCWs are also sources of health education for the public especially those who have symptoms and are seeking care. Thus, HCWs' knowledge, attitude and practice (KAP) related to COVID-19 can have direct impact on their own health as well as on the government's effort to contain the spread of the disease and mitigate its public health consequences. ${ }^{10}$ Misunderstanding of the disease among HCWs, negative attitudes towards governments' effort to manage it and any underestimation of its risks can all result in increased spread of infection and worse clinical, economic and social outcomes. Frontline HCWs in Nigeria include doctors, nurses, midwives, medical laboratory scientists, pharmacists and in a lot of rural and semiurban communities, patent and proprietary medicine vendors who are often the first point of contact for the medical careseeking public and a main source of treatments for acute conditions. ${ }^{11-14}$

Understanding HCWs' KAP about the COVID-19 pandemic at different healthcare delivery settings can help policy-makers and healthcare agencies understand their knowledge gaps and training needs. It can also help in the planning, design and implementation of mitigation strategies such as contact tracing, compliance with universal precautions, vaccine advocacy and immunisation campaigns. ${ }^{1516}$

There are few studies on the KAPs related to COVID-19 among various cadres of frontline HCWs in Nigeria. In their study, Ejeh et $a l^{17}$ reported 'excellent knowledge' about COVID-19 among HCWs but noted some areas of 'poor knowledge, negative attitudes and unacceptable practices'. Notably, there was poor knowledge about potential protection from COVID-19 due to Africans' genetic makeup, the role of prayer in curing COVID-19 and the protective effect of mask wearing. However, a majority of their samples were veterinary doctors. In their study of HCWs, Mbachu et $a l^{18}$ reported 'good knowledge' and 'preventive practice' but 'poor and indifferent attitude' (exemplified by lack of interest in work and fear of going to work due to COVID-19) among their respondents. However, it was conducted in one state in south eastern Nigeria.

This is a national study to evaluate the KAPs related to COVID-19 among frontline HCWs across different regions in Nigeria including their perceived COVID-19 training needs and preferences. We hypothesised that KAPs will vary by region or work setting, while training needs and preferences will vary by professional group.

\section{METHODS}

\section{Study design and study participants}

This was a nationwide, cross-sectional, secure, anonymous online survey conducted from 16 July to 1 August 2020, with electronic link of the survey shared with HCWs associations in Nigeria on their WhatsApp groups, Facebook pages and Twitter accounts after formal emails, letters, phone outreach and consultation with the leadership of each association by members of the research group. The survey was designed to take an average of $10 \mathrm{~min}$ to complete. The study survey link was sent electronically to all the target professional organisations across the six geopolitical zones in Nigeria (south-east, south-south, south-west, north-west, north-east and north-central) and the Federal Capital Territory, Abuja. Respondents were eligible to participate if they were nurses, doctors, clinical laboratory scientists or pharmacists actively working in any clinical setting with direct patient contact. Data collection was done through the electronic link and automatically transmitted and stored on Yale University's Yale Qualtrics Survey Secure Database.

\section{KAP survey design}

The survey consisted of two parts, the first part contained six items covering respondents' sociodemographics and work setting. The second part of the survey contained 33 items that assessed the respondents' KAP and training needs and preferences related to the COVID-19 pandemic.

There were nine items that focused on knowledge of COVID-19 symptoms, transmission, treatment and prevention. Attitude and beliefs about the pandemic were assessed by 10 items, while personal and clinical practice were assessed by 12 items. The final two items asked about respondents' COVID-19 training needs and preferred mode of receiving the training. All KAP items (except two items that pertained to source of information on COVID-19 and knowledge of the clinical symptoms) were recorded on a Likert Scale ranging from 1 to 5 (strongly agree to strongly disagree). The two items on source of information and clinical symptoms as well as the last two items on training needs and preferences offered multiple-choice answers with respondents able to select more than one answer. The items also had a freetext option (online supplemental appendix 1).

The items were developed using the 2020 WHO and NCDC guidelines about the pandemic ${ }^{25}$ with some items adapted from previously published surveys. ${ }^{18} 19$ Overall survey development and design was guided by framework from the US Department of Education's Institute of Educational Sciences ${ }^{20}$ (figure 1). The survey items were pretested among eight volunteer representative HCWs, then were piloted among additional 20 volunteer representative HCWs. Iterations to the survey items, design and administration were made based on the feedback from the pretesting and piloting.

\section{Statistical analysis}

First, data cleaning was completed to identify errors and to remove data that were incorrect, incomplete, irrelevant, 


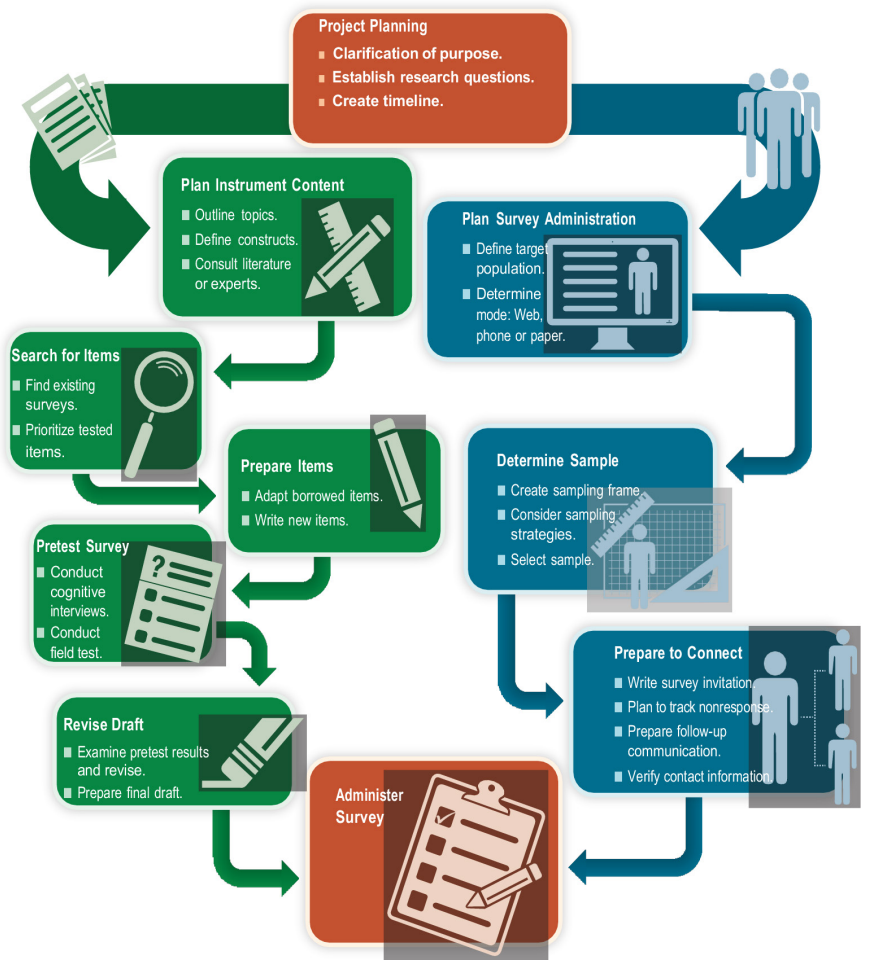

Figure 1 Study survey development and design process. The figure outlines the process from project planning, survey content development, testing to administration.

duplicated or improperly formatted. Only data from respondents who completed all items of the survey were included in the data analysis. Next, descriptive statistics were computed to summarise respondents' self-reported sociodemographic characteristics including gender, age, category of health worker, level of education, years in practice and location of practice. Age groups, HCWs groups and educational attainment were organised for clarity and simplification of analysis. Second, $\chi^{2}$ tests were conducted to compare four groups of HCWs across all sociodemographic characteristics.

Third, an exploratory factor analysis (EFA) with the maximum likelihood extraction method was used to identify the underlying set of dimensions of survey responses to the KAP questions. Orthogonal rotations were applied to the initial factor solution to identify the simple structure for interpretation. ${ }^{21}$ Sampling adequacy for factor analysis was assessed with the Kaiser-Meyer-Olkin (KMO) measure and Bartlett's test. ${ }^{22}$ Individual loadings of 0.4 or greater were used in the factor determination. Extracted factors were examined and named based on analysis of the items loading on each factor. Cronbach's $\alpha$ was calculated to estimate the internal consistency of the items constituting each factor. ${ }^{23}$ Factors scores were calculated.

Fourth, analysis of covariance using general linear modelling procedure was used to identify differences in factor score among four groups of HCWs with factor scores as a dependent variable and group membership as an independent variable. These analyses were adjusted for significant differences in sociodemographic characteristics $($ at $\mathrm{p}<0.05)$. T-tests were then used to examine factor scores of the groups in pairwise comparisons. All analyses were performed using SAS V.9.4 statistical software (SAS Institute). Statistical significance was evaluated at the 0.05 level.

\section{Patient and public involvement \\ No patient involved.}

\section{RESULTS}

Analytic sample consisted of 1852 individuals out of a possible 2500 (response rate of 74\%) participants from the professional associations' membership list. Among them, 52\% ( $n=923)$ were female. Majority of the respondents $(69.2 \%)$ were young (18-33 years old), $23.4 \%$ were 34-49 years old and $7.4 \%$ were 50 years and older.

Over two-thirds of the sample reported a hospital as a primary place of work (72\%), with others reporting workplaces as being a health centre $(12.1 \%)$ or pharmacy and medicine shop (15.9\%). The majority of the samples $(68.3 \%)$ were practicing in the southern part of the country, $23.4 \%$ in the north and $8.3 \%$ were in the federal capital territory. One-third of the sample had a fellowship certificate, diploma or MBBS (35.5\%); $25.7 \%$ had bachelor's degree; $20.3 \%$ had nurse certificate (registered nurse or Bachelor of Nursing); 9.2\% had a primary or secondary school certificate; $6.9 \%$ had master's degree and $2.3 \%$ had a $\mathrm{PhD}$ diploma.

For the subsequent analysis, respondents were subcategorised into four groups: doctors $(36.6 \%$; $\mathrm{n}=616)$, nurses $(37 \% ; \mathrm{n}=623)$, pharmaceutical professionals $(12.9 \% ; \mathrm{n}=217)$ and laboratory technician or scientist $(13.5 \% ; n=228)$. Significant differences between the groups were observed in age, gender, education, place of practice and place of work (table 1).

Maximum likelihood EFA was performed on the sample of 1852 individuals, to extract the underlying factor structure of KAP survey. The number of participants was considered reasonable for factor analysis, exceeding the minimum number of 300 cases as suggested by Tabachnick \& Fidell (2007). An examination of the Kaiser-Meyer-Olkin (KMO) measure of sampling adequacy (MSA) suggested that the sample was factorable (overall measure of sampling adequacy $(\mathrm{MSA})=0.87) .{ }^{22}$ Inspection of the pattern of eigenvalues and the scree plot suggested that four factors explained most of the variability and were retained for investigation. Based on the orthogonal rotation factor solution with a 0.4 factor loading criterion and scree plot criterion, four factors were identified representing KAP and prevention related to COVID-19. High loadings were evident for the eight positive outcome items on the first factor that included eight items related to safety and prevention of COVID-19 and was labelled safety and prevention (factor 1) (Cronbach's $\alpha=0.78$ ). The second factor included six items reflecting knowledge about risk factors of COVID-19 transmission and was labelled 
practice and knowledge (factor 2) (Cronbach's $\alpha=0.77$ ). The third factor included four items that focus on use of personal protective equipment (PPE) and access to COVID-19 testing. It was labelled control and mitigation (factor 3) (Cronbach's $\alpha=0.70$ ). The fourth factor included four items specifically related to perceptions about COVID-19 in the Nigerian national environment and was labelled national perceptions (factor 4) (Cronbach's $\alpha=0.66$ ). Individual factor loading and factor patterns are shown in table 2 .

Significant differences between the four groups of HCWs were found on three factors: safety and prevention (factor 1) $\left(\mathrm{F}_{1,1655=} 5.79, \mathrm{p}=0.0006\right)$, control and mitigation (factor 3) $\left(\mathrm{F}_{1,1633=} 12.9, \mathrm{p}<0.0 .0001\right)$ and national perceptions (factor 4) $\left(\mathrm{F}_{1,1655}=7.31, \mathrm{p}<0.0001\right)$ with doctors scoring significantly higher on these three factors compared with other groups (table 3). More specifically, doctors scored higher than nurses and pharmaceutical workers on safety and prevention (factor 1); doctors also scored higher than nurses, pharmaceutical workers and laboratory workers on control and mitigation (factor 3), with nurses having a higher score than pharmaceutical workers. Additionally, doctors had a higher score on national perceptions (factor 4) as compared with laboratory workers and nurses.
Regarding identification of the main clinical symptoms of COVID-19, the most popular response was fever as identified by $78.6 \%$ of HCWs followed by cough $(69.3 \%)$, sneezing $(58.4 \%)$, sore throat $(52.2 \%)$, headache $(49.1 \%)$, runny nose $(37.5 \%)$, smell disturbance $(33.7 \%)$, taste disturbance $(30.2 \%)$, muscle pain $(20.8 \%)$, diarrhoea $(17.7 \%)$ and confusion $(7.1 \%)$. These items were not mutually exclusive.

Overall, the most endorsed sources of information about COVID-19 were official governmental sites (eg, the NCDC, ministry of health) (61.7\% of respondents). However, others received this information through the news media (eg, television, radio, newspaper) (53.2\%), official international health organisations (eg, WHO) websites (52.4\%), social media (eg, Facebook, Twitter, WhatsApp) $(45.1 \%)$, seminars $(30 \%)$, a friend $(17.6 \%)$ and journals $(17.5 \%)$. Doctors reported that they received COVID-19-related information from WHO $(60.9 \%)$ and official government websites (64.3\%), news media $(50.0 \%)$, social media $(45.0 \%)$, scientific journals $(27.3 \%)$ and seminars $(32.9 \%)$. Nurses reported that they received majority of the information about COVID-19 from NCDC (60.1\%), WHO (47.7\%), news media $(58.6 \%)$, social media $(47.7 \%)$, seminars $(26.8 \%)$ and journals $(10.9 \%)$. Most popular source of

Table 1 Sociodemographic characteristics stratified by groups of healthcare workers

\begin{tabular}{|c|c|c|c|c|c|c|c|c|c|c|}
\hline \multirow[b]{2}{*}{ Variable } & \multicolumn{2}{|c|}{$\begin{array}{l}\text { Doctors ( } n=166 \text {; } \\
36.6 \%)\end{array}$} & \multicolumn{2}{|c|}{$\begin{array}{l}\text { Nurse }(n=623 ; \\
37 \%)\end{array}$} & \multicolumn{2}{|c|}{$\begin{array}{l}\text { Pharma }(n=217 \text {; } \\
12.9 \%)\end{array}$} & \multicolumn{2}{|c|}{$\begin{array}{l}\text { Laboratory } \\
\text { workers } \\
(n=228 ; 13.5 \%)\end{array}$} & \multicolumn{2}{|c|}{ Statistical test } \\
\hline & $\mathbf{n}$ & $\%$ & $\mathbf{n}$ & $\%$ & $\mathbf{n}$ & $\%$ & $\mathbf{n}$ & $\%$ & $\times 2$ & $\mathbf{P}$ \\
\hline Age groups (years) & & & & & & & & & 114.41 & $<0.0001$ \\
\hline $18-33$ & 334 & 54.22 & 484 & 77.69 & 159 & 73.27 & 191 & 83.77 & & \\
\hline $34-49$ & 213 & 34.58 & 115 & 18.46 & 41 & 18.89 & 26 & 11.40 & & \\
\hline Gender & & & & & & & & & 145.79 & $<0.0001$ \\
\hline Male & 369 & 59.90 & 183 & 29.37 & 120 & 55.3 & 143 & 62.72 & & \\
\hline Female & 247 & 40.10 & 440 & 70.63 & 97 & 44.70 & 85 & 37.28 & & \\
\hline Education & & & & & & & & & 849.02 & $<0.0001$ \\
\hline School certificate & 35 & 5.80 & 48 & 7.80 & 45 & 21.03 & 9 & 3.96 & & \\
\hline Nurse certificate & 27 & 4.48 & 306 & 49.76 & 11 & 5.14 & 3 & 1.32 & & \\
\hline Medical degree & 266 & 44.11 & 12 & 1.95 & 16 & 7.48 & 10 & 4.41 & & \\
\hline Region of practice & & & & & & & & & 73.814 & $<0.0001$ \\
\hline FCT Abuja & 76 & 12.34 & 25 & 4.01 & 18 & 8.29 & 22 & 9.65 & & \\
\hline North region & 183 & 29.71 & 101 & 16.21 & 59 & 27.19 & 55 & 24.12 & & \\
\hline South region & 357 & 57.95 & 497 & 79.78 & 140 & 64.52 & 151 & 66.23 & & \\
\hline Place of work & & & & & & & & & 512.79 & $<0.0001$ \\
\hline Hospital & 466 & 75.65 & 500 & 80.26 & 62 & 28.57 & 189 & 82.89 & & \\
\hline Health centre & 92 & 14.94 & 72 & 11.56 & 8 & 3.69 & 29 & 12.72 & & \\
\hline
\end{tabular}


Table 2 Factor pattern and items loading

Safety and prevention (factor 1 )

Factor 1 Factor 2 Factor 3 Factor 4

Using alcohol-based hand sanitizers can prevent one from contracting

0.7665

COVID-19.

Washing hands with soap and running water for 20 s can prevent one from

0.7410

contracting COVID-19.

Wearing face mask can prevent COVID-19 infection.

0.6065

Isolation of people who are infected with the COVID-19 is an effective way to 0.5641

reduce the spread of the virus.

To prevent spread of COVID-19, people should avoid going to crowded places $\quad 0.5275$

(eg, marketplace, shopping mall, banks, etc).

My safety will be my concern if I must attend to a patient with signs and $\quad 0.4591$

symptoms of COVID-19.

To finally defeat COVID-19, the use of a vaccine is critical and should be $\quad 0.4520$

encouraged.

When it is available, I will readily accept COVID-19 vaccine and recommend it to 0.4026

my patients.

Practice and knowledge (factor 2)

I am aware that my workplace has sent at least one patient to be tested for

COVID-19.

I know where to send someone for COVID-19 test.

0.7181

I have worn a mask whenever I am in contact with patients.

0.6553

0.6032

I have worn a mask whenever I am in a public place.

0.5235

I have not been shaking hands with people.

0.5235

I have avoided contacting family members immediately after coming home from

0.4166

work.

Control and mitigation (factor 3)

All staff at work have been trained on how to put on and take off the PPE.

0.7966

At my place of work, PPE is easily accessible to all staff that need them to see

0.7943 patients.

Any healthcare worker in my place of work exposed to COVID-19 gets tested for

0.5737

COVID-19.

In recent days, I have avoided patients with signs and symptoms that look like

COVID-19.

National perceptions (factor 4)

COVID-19 is not a 'big man's' disease.

0.7932

COVID-19 is not a 'white man's' disease and so Africans are not protected from

0.7797

it.

COVID-19 is worse than the problems of hunger and poverty in Nigeria.

0.6162

If a person with COVID-19 does not have fever, he/she can transmit the virus to

0.4087 others.

PPE, personal protective equipment.

information among pharmaceutical workers were NCDC $(62.7 \%)$, WHO $(48.4 \%)$, news media $(53.0 \%)$, social media $(45.2 \%)$, seminars $(24 \%)$, and scientific journals $(14.3 \%)$. Finally, for medical laboratory scientists, the most endorsed sources of information were NCDC $(79.4 \%)$, WHO (67.5\%), news media (61.4\%), social media $(57.5 \%)$, health educational seminars $(50.4 \%)$ and scientific journals $(19.3 \%)$. The choices were not mutually exclusive.
With regards to training needs, doctors would like to have additional trainings in all aspects of COVID-19 mitigation strategies indicated, specifically on how to use PPE $(55.6 \%)$, how to reorganise workplace to prevent spread of the infection $(52.8 \%)$, how to disinfect workplace to prevent spread $(51.8 \%)$ and how to screen the patients $(49.5 \%)$. The most preferred mode of training was webinars $(51.9 \%)$, followed by conferences $(47.4 \%)$, staff ward meetings $(40 \%)$ and in-person hands-on training $(34.7 \%)$. 
Table 3 Comparison of healthcare workers groups on COVID-19-related knowledge, attitude and practice factors

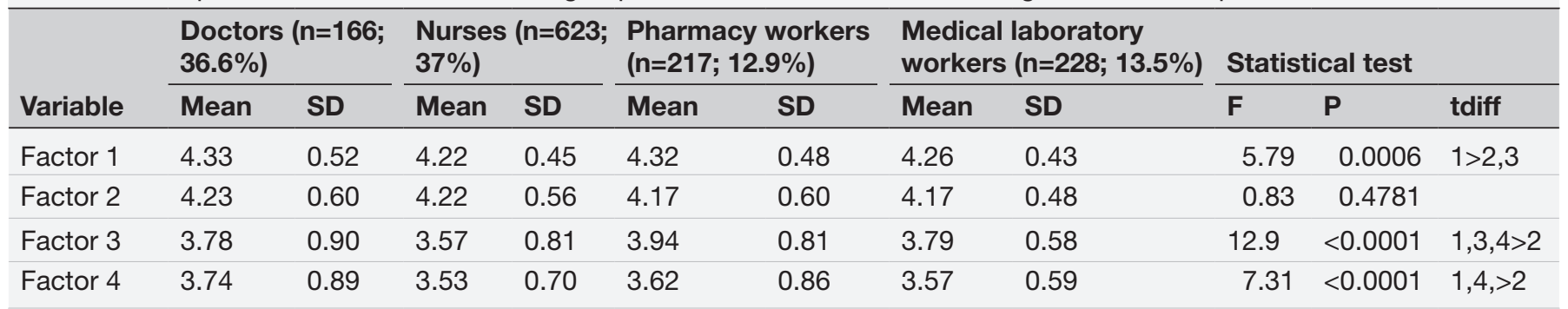

Nurses similarly requested additional training on workplace reorganisation $(51.7 \%)$, screening $(50.9 \%)$, PPE use $(47.7 \%)$ and disinfection $(42.2 \%)$. They preferred to receive additional training through conferences $(55.1 \%)$, webinars $(49.1 \%)$, staff meetings $(46.4 \%)$ and hands-on training $(31.5 \%)$.

Pharmaceutical professionals indicated need for more training in workplace reorganisation $(51.6 \%)$, screening $(50.7 \%)$, disinfection $(49.3 \%)$ and use of PPE (46.1\%). Many of them wanted to receive the trainings in forms of conferences $(52.2 \%)$ or webinars $(45.2 \%)$, staff meetings $(31.8 \%)$ and hands-on training $(29.5 \%)$.

The medical laboratory professionals mostly indicated need of additional training workplace reorganisation $(61.8 \%)$ and disinfection $(43 \%)$. Other medical laboratory professionals cited need for training on use of PPE $(35.1 \%)$ and screening $(39.5 \%)$. They preferred to receive these trainings at conferences $(74.5 \%)$ or through webinars $(63.2 \%)$. Staff meetings $(23.1 \%)$ and in-person hands-on training $(17.1 \%)$ were the least chosen options. Respondents could select multiple answers; thus, choices do not sum up to $100 \%$.

\section{DISCUSSION}

In this cross-sectional national survey of various cadres of frontline HCWs from all parts of Nigeria, factor analysis of the questionnaire items and subsequent inspection of eigenvalues and the scree plot suggested a four-factor structure related to their COVID-19 KAP as follows: safety and prevention, practice and knowledge, control and mitigation and national perceptions. Although there were some significant differences among different cadres of HCWs, most respondents had a good understanding of the basic facts about COVID-19 including its clinical presentation, mode of spread and prevention measures. These findings suggest that public health campaigns embarked on by the responsible health agencies since the beginning of the COVID-19 pandemic have had the expected positive impact on HCWs. However, our findings show differences in KAPs across HCWs with doctors scoring higher on safety and prevention, control and mitigation and national perceptions relative to other groups. This suggests that more efforts should be geared towards enhancing KAP related to COVID-19 among non-physician frontline HCWs through educational interventions tailored to their specific training needs and delivered through accessible platforms. Addressing this knowledge gap is important as non-physician HCWs such as nurses have relatively more frequent direct contact with patients and are therefore more likely to contract COVID-19 especially in acute care settings. ${ }^{24}{ }^{25}$ Nurses scored higher than medical laboratory scientists on factor 3 which include items related to PPE indicating that nurses are more knowledgeable about PPE and its usage perhaps due to more direct experience with patients with COVID-19.

The most recognisable symptoms/signs of COVID-19 among respondents were fever, cough, sneezing and sore throat. The least recognised symptoms/signs were confusion, diarrhoea, muscle pain and sensory disturbance. While evidence on the various acute manifestations of COVID-19 is accumulating, current data suggest that these commonly recognisable individual symptoms have poor diagnostic properties. ${ }^{26}$ Continuing professional education for HCWs is necessary to keep them up to date on the various symptoms and signs of COVID-19 as data become available. Additionally, because these easily recognisable symptoms and signs can be presentations of other viral respiratory or systemic illnesses, wide availability of definitive tests for COVID-19 is essential for early identification, treatment, contact tracing and prevention protocols. ${ }^{27}$ The need for high testing capacity is particularly relevant in low-income and middle-income countries such as Nigeria that have limited capacity for intensive care for severe illness but higher capacity for prevention, early identification and treatment of mild COVID-19 symptoms. ${ }^{28}$ Lessons learnt during the 2014 Ebola outbreak in Nigeria, namely, instituting local, immediate and culturally sensitive public health measures accompanied by massive public enlightenment campaign tailored to the local environment, are particularly relevant here as the country grapples with the scale and impact of the COVID-19 pandemic. ${ }^{29}$

Notably, a vast majority of participating HCWs were aged less than 40 years with laboratory scientists and nurses having the largest proportion of those under age 40 years. This reflects perhaps the largely young population and workforce in Nigeria. ${ }^{30}$ This finding has relevance in the mode of delivery of public health information, training and staff engagement related to COVID-19. As shown in our results and other studies of health informationseeking behaviour in Nigeria, younger people are more 
likely to seek information and engage with topical issues on social media compared with more formal sources of information such as scientific journals and government websites. ${ }^{31} 32$ Therefore, continuing professional development and training on COVID-19 targeted at HCWs should incorporate strategies for social media engagement, online sources of accurate information and support for internet access.

Our results showed that all groups of HCWs surveyed wanted additional trainings on COVID-19 screening, prevention and mitigation strategies. However, different groups emphasised different areas of training reflecting the need to adapt and tailor COVID-19 training to the local needs of specific groups of HCWs such that it will be relevant to their everyday practice. This approach is supported by recent studies on COVID-19 and HCWs in low-resource settings. ${ }^{33}{ }^{34}$ Different groups also endorsed varying preference for modes of training. The most popular modes of training among all the groups were scientific conferences and webinars and the least popular was in-person hands-on training. This is an indication of the HCWs' yearning for accurate data related to the COVID-19 pandemic and the popularity of remote/ online learning necessitated by related social distance requirements and lockdowns. ${ }^{35}$

One of the limitations of this study is the non-random sampling procedure used. This was a convenience sample of frontline HCWs who were willing and able to complete the electronic survey and therefore may not be representative of all frontline HCWs in Nigeria. Also, there could have been potential selection effects among doctors, those working in hospital settings, southern Nigeria and younger people who were more likely to complete this survey. However, it was a large sample and had respondents with varying educational backgrounds working in different healthcare settings and locations across Nigeria. A second limitation relates to the non-standardised questionnaire. Items were adapted from the WHO COVID-19 diagnosis criteria and published literature. However, four factors with high internal consistency were identified that adequately represented COVID-19 KAP and prevention strategies.

Third, we used limited number of questions based on early and evolving data on COVID-19 to measure KAP.

Further studies are needed on KAP among frontline HCWs that incorporate current data on COVID-19 risk factors, presentation, spread, prevention and treatment. It will also be insightful to complete a follow-up survey among the same respondents to assess any changes in their KAP as more knowledge accumulate and medical practice related to COVID-19 changes.

\section{CONCLUSION}

Our study is the first nationwide, cross-sectional survey of frontline HCWs in Nigeria on the COVID-19 pandemic. It established a four-factor structure on HCWs KAP related to COVID-19. Our findings show that as the COVID-19 outbreak in Nigeria continues to evolve, HCWs displayed good basic knowledge of COVID-19, a positive attitude and adherence to good practices regarding the pandemic but with substantial differences among different groups. There were also group differences on COVID-19 training needs and preferences. There is need for tailored health education and training aimed at improving COVID-19 KAP, particularly among non-physician HCWs. As the pandemic continues to evolve, continuing professional development policies by various professional licensing agencies should consider changes that make continued licensing contingent on up-to-date education and training on all aspects of the COVID-19 pandemic.

\section{Author affiliations}

${ }^{1}$ Department of Psychiatry, Yale University School of Medicine, New Haven, Connecticut, USA

${ }^{2}$ Department of Family Medicine, Franciscan Physician Network, Crown Point, Indiana, USA

${ }^{3}$ Department of Orthopaedics, National Orthopaedic Hospital Enugu, Enugu, Nigeria ${ }^{4}$ Department of Internal Medicine, University of Nigeria Teaching Hospital, Enugu, Nigeria

${ }^{5}$ Department of Family Medicine, Catterick and Colburn Medical Group, Richmondshire, NHS North Yorkshire, Yorkshire and Humber, England, UK ${ }^{6}$ Department of Family Medicine, Meadow Primary Health Care Center, Saskatchewan Health Authority, Regina, Saskatchewan, Canada

${ }^{7}$ Department of Psychiatry, VA Connecticut Healthcare System, West Haven, Connecticut, USA

${ }^{8}$ Department of Cardiology, University of Port Harcourt Teaching Hospital, Port Harcourt, Nigeria

${ }^{9}$ Department of Medicine, Alex Ekwueme Federal Teaching Hospital Abakaliki, Abakaliki, Ebonyi, Nigeria

${ }^{10}$ Department of Radiology, University of Calabar Teaching Hospital, Calabar, Nigeria

${ }^{11}$ Department of Physiology, University of Nigeria, Enugu, Enugu, Nigeria

${ }^{12}$ Department of Otorhinolaryngology, Alex Ekwueme Federal University Teaching Hospital Abakaliki, Abakaliki, Ebonyi, Nigeria

${ }^{13}$ Department of Medicine, Abbeyfields Medical Center, Colchester, East England, UK ${ }^{14}$ Department of Radiology, Imo State University Teaching Hospital, Orlu, Nigeria

Contributors TI, UGO, UEA, PON, AIA, KI, NNU, GI, CC, UBA, TTM, CO-E and EOI conceptualised, designed and implemented the study, completed data collection and manuscript preparation. TI, AJ, AH, ES and GAS completed data cleaning, data analysis and contributed to manuscript preparation.

Funding The authors have not declared a specific grant for this research from any funding agency in the public, commercial or not-for-profit sectors.

Competing interests None declared.

Patient consent for publication Consent obtained directly from patient(s).

Ethics approval This study was reviewed and approved by the Research Ethics Committee of Imo State University Teaching Hospital, Orlu, Imo State (\# IMSUTH/ $\mathrm{CS} / 121)$.

Provenance and peer review Not commissioned; externally peer reviewed.

Data availability statement Data are available in a public, open access repository. Data availability statement: Deidentified participants data, research protocol and statistical analysis plan are are available upon reasonable request from https:// orcid.org/0000-0002-7538-3611.

Supplemental material This content has been supplied by the author(s). It has not been vetted by BMJ Publishing Group Limited (BMJ) and may not have been peer-reviewed. Any opinions or recommendations discussed are solely those of the author(s) and are not endorsed by BMJ. BMJ disclaims all liability and responsibility arising from any reliance placed on the content. Where the content includes any translated material, BMJ does not warrant the accuracy and reliability of the translations (including but not limited to local regulations, clinical guidelines, terminology, drug names and drug dosages), and is not responsible for any error and/or omissions arising from translation and adaptation or otherwise. 
Open access This is an open access article distributed in accordance with the Creative Commons Attribution Non Commercial (CC BY-NC 4.0) license, which permits others to distribute, remix, adapt, build upon this work non-commercially, and license their derivative works on different terms, provided the original work is properly cited, appropriate credit is given, any changes made indicated, and the use is non-commercial. See: http://creativecommons.org/licenses/by-nc/4.0/.

\section{ORCID iDs}

Elina Stefanovics http://orcid.org/0000-0002-4536-433X

Anthony Ikenna Adimekwe http://orcid.org/0000-0003-1986-4258

Angela Haeny http://orcid.org/0000-0003-3004-6977

\section{REFERENCES}

1 Zhu N, Zhang D, Wang W, et al. A novel coronavirus from patients with pneumonia in China, 2019. N Engl J Med Overseas Ed 2020;382:727-33.

2 World Health Organization. Coronavirus disease 2019 (COVID-19): situation report, 80, 2020.

3 Dong E, Du H, Gardner L. An interactive web-based dashboard to track COVID-19 in real time. Lancet Infect Dis 2020;20:533-4.

4 University, J.H. Coronavirus resource center, 2020. Available: https:// coronavirus.jhu.edu/map.html [Accessed 23 May 2020]

5 Control, N.C.f.D. Covid-19 Nigeria, 2020. Available: https://covid19. ncdc.gov.ng/ [Accessed 23 May 2020].

6 Adam A-B. Nigeria: 113 healthcare workers infected with COVID-19. Available: https://www.aa.com.tr/en/africa/nigeria-113-healthcareworkers-infected-with-covid-19/1825398 [Accessed 31 May 2020].

7 Otto B. Combatting health worker infections in Nigeria. Kaduna, Nigeria: World Health Organization, 2020.

8 Bolashodun O. Tragedy as 2 more Nigerian doctors die of COVID-19, in MSN: Africa. Nigeria: Microsoft News, 2020.

9 Sim MR. The COVID-19 pandemic: major risks to healthcare and other workers on the front line. BMJ Publishing Group Ltd, 2020.

10 Bedford J, Enria D, Giesecke J, et al. COVID-19: towards controlling of a pandemic. Lancet 2020;395:1015-8.

11 Ademiluyi IA, Aluko-Arowolo SO. Infrastructural distribution of healthcare services in Nigeria: an overview. J Geogr Reg Plann 2009;2:104-10.

12 Beyeler N, Liu J, Sieverding M. A systematic review of the role of proprietary and patent medicine vendors in healthcare provision in Nigeria. PLoS One 2015;10:e0117165

13 Liu J, Prach LM, Treleaven E, et al. The role of drug vendors in improving basic health-care services in Nigeria. Bull World Health Organ 2016;94:267-75.

14 Sudhinaraset M, Ingram M, Lofthouse HK, et al. What is the role of informal healthcare providers in developing countries? A systematic review. PLoS One 2013;8:e54978.

15 Obagha C, Gidado S, Uba B, et al. Health workers knowledge, attitude and practice during Lassa fever outbreak, Anambra state, Nigeria, 2016. Int J Infect Dis 2018;73:204

16 Ekuma AE, Akpan IS. Lassa fever and infection control: knowledge, attitudes and practice in a university teaching hospital in Uyo, Nigeria. Ibom Med J 2017;10:40-7.

17 Ejeh FE, Saidu AS, Owoicho S, et al. Knowledge, attitude, and practice among healthcare workers towards COVID-19 outbreak in Nigeria. Heliyon 2020;6:e05557.
18 Mbachu CNP, Azubuike CM-C, Mbachu II, et al. COVID-19 infection: knowledge, attitude, practices, and impact among healthcare workers in a south-eastern Nigerian state. J Infect Dev Ctries 2020;14:943-52.

19 Zhong B-L, Luo W, Li H-M, et al. Knowledge, attitudes, and practices towards COVID-19 among Chinese residents during the rapid rise period of the COVID-19 outbreak: a quick online cross-sectional survey. Int J Biol Sci 2020;16:1745-52.

20 Walston J, Redford J, Bhatt M. Survey methods in education research: Facilitator's guidebook and workshop resources (REL 2017). Washington, DC: US Department of Education, Institute of Education Sciences. National Center for Education Evaluation and Regional Assistance, Regional Educational Laboratory Midwest, 2017. https://ies.ed.gov/ncee/edlabs

21 Kaiser HF. The varimax criterion for analytic rotation in factor analysis. Psychometrika 1958;23:187-200.

22 Pett MA, Lackey NR, Sullivan JJ. Making sense of factor analysis: the use of factor analysis for instrument development in health care research. Sage, 2003.

23 Cronbach LJ. Coefficient alpha and the internal structure of tests. Psychometrika 1951;16:297-334.

24 Nguyen LH, Drew DA, Graham MS, et al. Risk of COVID-19 among front-line health-care workers and the general community: a prospective cohort study. Lancet Public Health 2020;5:e475-83.

25 Iversen K, Bundgaard H, Hasselbalch RB, et al. Risk of COVID-19 in health-care workers in Denmark: an observational cohort study. Lancet Infect Dis 2020;20:1401-8.

26 Struyf T, Deeks JJ, Dinnes J, et al. Signs and symptoms to determine if a patient presenting in primary care or hospital outpatient settings has COVID-19 disease. Cochrane Database Syst Rev 2020;7:CD013665.

27 George PE, Stokes CL, Bassit LC, et al. Covid-19 will not "magically disappear": Why access to widespread testing is paramount. Am J Hematol 2021;96:174-8.

28 Hopman J, Allegranzi B, Mehtar S. Managing COVID-19 in low- and middle-income countries. JAMA 2020;323:1549-50.

29 Oleribe OO, Salako BL, Ka MM, et al. Ebola virus disease epidemic in West Africa: lessons learned and issues arising from West African countries. Clin Med 2015;15:54-7.

30 Bandura R, Hammond M. The future of global stability: the world of work in developing countries. Center for Strategic and International Studies, 2018.

31 Ezika EA, Cross B, Lewitt M. Sources of cardiovascular health information and channels of health communication among urban population in Nigeria. IJPHS 2018;7:72-80.

32 Obasola OI, Agunbiade OM. Online health information seeking pattern among undergraduates in a Nigerian university. Sage Open 2016:6:215824401663525.

33 Elhadi M, Msherghi A, Alkeelani M, et al. Assessment of healthcare workers' levels of preparedness and awareness regarding COVID-19 infection in low-resource settings. Am J Trop Med Hyg 2020;103:828-33.

34 Alao MA, Durodola AO, Ibrahim OR, et al. Assessment of health workers' knowledge, beliefs, attitudes, and use of personal protective equipment for prevention of COVID-19 infection in lowresource settings. Adv Public Health 2020;2020:1-10.

35 Dhawan S. Online learning: a panacea in the time of COVID-19 crisis. J Educ Technol Syst 2020;49:5-22. 